Kyoto University,

Graduate School of Economics

Research Project Center Discussion Paper Series

Fairness Ideals, Hidden Selfishness and Opportunist Behavior:

An Experimental Approach

Natsuka Tokumaru

Discussion Paper No. E-14-004

Research Project Center

Graduate School of Economics

Kyoto University

Yoshida-Hommachi, Sakyo-ku

Kyoto City, 606-8501, Japan

April, 2014 


\title{
Fairness Ideals, Hidden Selfishness, and Opportunistic Behavior: \\ An Experimental Approach \\ Natsuka Tokumaru
}

\begin{abstract}
Economic experiments have shown that human incentives are not only limited to the profit-maximizing principle but also motivated by fairness. Those studies presuppose that individuals commit to fixed value systems and that experimental institutions invoke fairness ideals. This paper shows that participants strategically select fairness ideals advantageous for self-distribution. Participants whose relative earnings are higher than those of their pairs adhere to a liberalist fairness ideal, whereas those with lower relative earnings prefer an egalitarian distribution of money. This reflects that individuals commit opportunistic behavior as a result of resolving a cognitive dissonance between material utility and fairness.

Keywords: Economic Experiment, Fairness Ideals, Cognitive Dissonance, Hidden Selfishness, Opportunistic Behavior
\end{abstract}

\section{Introduction}

Studies involving economic experiments such as the dictator game, or the ultimatum game, requiring participants to distribute a certain amount of money to the other participant have shown that human incentives are not only limited to the profit-maximizing principle, but are also motivated by other ethical values as recipriocity or ideals of fairness (Kahneman et al. 1986; Forsythe et al. 1994; Levin 1998; Fehr \& Schmidt 1999). Those studies show that only limited numbers of participants conform to the homo economics prediction; in most experiments, less than one-third of the participants distributed all the money to themselves, and the rest of the participants decided to leave some amount of money to their pairs.

Other studies on distribution experiments followed by production suggest that participants act upon various types of fairness ideals such as egalitarianism, liberalism, or utilitarianism in their decision making (Hoffman et al. 1985; Cappelen et al. 2007). A strict egalitarian participant would divide team income 50-50 with his or her pair, whereas a strict liberalist participant would distribute team income according to the amount each member has earned in production process. Those who are strict utilitarians would leave nothing for their pairs.

Those studies mentioned above presuppose that i) each individual preliminarily commits to a certain fixed value system and ii) a certain experimental institution invokes a certain fairness ideal as a distribution principle, according to which individuals distribute certain amounts of money to their 
pairs ${ }^{1}$. Here it is presumed that, under a certain experimental institution (e.g., game rules, environments, payment procedures), a certain participant would always commit to a certain specific fairness ideal such as egalitarian distribution.

Since it is presupposed that experimental institutions trigger each individual's fairness ideal, previous studies attempted to examine which factors are definitive for a participant's commitments to fairness ideals by changing the experimental institution and then comparing the results. For instance, Hoffman (1985) states that a participant tends to justify a higher amount of self-distribution if a production method satisfactorily reflects that participant's ability and efforts. Cherry et al's (2002) experiments reveal that when anonymity is maintained, and when participants earn money by their ability and efforts, (taking the required score by GMAT) most of them (more than $90 \%$ ) distribute all the earned money amount to themselves and leave nothing to their pairs. However, questions arise as to whether individuals always follows a certain given value system in a fundamentalist way in a given experimental institution.

By performing a distribution experiment with production, this paper aims to show that some individuals tend to pursue opportunistic behavior, which strategically selects the more advantageous distribution principle from other possible options (i.e., opportunity sets) under the same experimental institution. Williamson (1975) suggests that individuals commit to opportunism, which does not follow an established or coherent ethical standard, but rather takes advantages of opportunities in a given transaction process. Opportunists do not deviate from social norms or from rules (and social reputation could represent an important incentive); however, opportunists are strategic and try to take an advantage of opportunities in a given social situation-a behavior that can be described as 'self-interest seeking with guile' (p. 26). ${ }^{2}$ According to the experimental results of this paper, a significant number of participants whose relative earnings are lower than their pairs' tend to commit to an egalitarian distribution; while participants with higher relative earnings display a significant tendency to commit a to liberalist distribution. This is because egalitarian distribution brings higher income to participants with lower relative earnings, and vice versa, because liberalist distribution brings higher income to the participants with higher relative earnings. These experimental results imply that participants recognized two possible distributional opportunities of egalitarian and liberalist fairness ideals, and that they strategically "select” the more advantageous one.

\footnotetext{
${ }^{1}$ Hoffman (1985) states that participants "would concur with a particular concept of fairness in distribution" in advance of the experiments, and that a participant "perceives the experimental institutions as triggering a particular aspect of his concept of justice," then "implements his perceptions of a fair distribution” (p. 260)

${ }^{2}$ Williamson (1975) approaches the concept from a theoretical perspective, explaining the internal market in terms of transaction costs and opportunistic behaviors. However, this paper does not go into detail in this point.
} 
This paper also attempts to examine the empirical validity of the model proposed by Fehr \& Schmidt (1999), which is introduced for explaining distributional behavior and individuals' value function in terms of the linear combination of one's material utility and the negative utility triggered by a deviation from a certain fairness ideal (see also Konow 2000; Bolton \& Ockenfels 2000). The Fehr \& Schmidt model presupposes that one's optimum distribution amount can be defined as such that "some extra amounts by selfish incentive" is added to an ideal amount of a certain fairness ideal. However, the experimental result of this paper shows that individuals have a significant tendency to exclusively commit to one distribution principle-either it is strict utilitarianism or other fairness ideals- and thus the value function of the Fehr \& Schmidt model cannot satisfactory explain the result $^{3}$. According to this paper, this tendency is an outcome of individuals' efforts to resolve a cognitive dissonance between material utility on the one hand and fairness ideals on the other, by committing to opportunistic behavior.

The structure of this paper is as follows: I will first provide an explanation of the design of the experiment (section 2). I shall also explain models of fairness ideals and the value functions (section 3) and then report on the experimental results (section 4). After discussing the opportunistic behavior and cognitive dissonance in the experimental results (section 5), I will advance the conclusions (section 6).

\section{Experimental Design}

By modifying the experiments of Cappelen et al. (2007), I performed experiments consisting of a production stage and a distribution stage six times from November 2011 to July 2013 in the laboratory of Kyoto Sangyo University in Japan ${ }^{4}$. Participants were assembled from undergraduate students at Kyoto Sangyo University including all departments, and the total number of participants was 134. Each experiment took approximately 30 minutes, including the instructions. Before the game started, an experimenter read aloud an introduction describing the rule (see Appendix), and the participants could ask questions if anything was left unclear. The experiment started after all participants understood the rules. In the experiments, participants were asked to play a one-shot game consisting of a production and a distribution. During the game, each participant was randomly matched with another participant, thus forming a team of two players. Participants knew that each of them had another team member, but the experiment was designed so that all of participants, including an experimenter, could not know whose pair was whose during and after the experiment. The details of the game are as follows:

${ }^{3}$ Fehr \& Schmidt (1999) themselves admit the linear model is not completely compatible with experimental observations (p. 847).

${ }^{4}$ This experiment is performed using an experimental program z-tree (Fischbacher 2007) 


\section{Production stage}

In the production stage, participants were asked to earn a certain amount of points, and the total income earned by team members at this production stage resulted in team earnings. Each participant was given 300 points as an initial endowment. Participants were asked to invest their endowment on a 100-points basis (i.e., they could invest 0, 100, 200, or 300 points). The rest of the points not invested were counted in the final payoff to a participant. After deciding the investment amount, each participant automatically derived a lotto number from a computer program, which attributed "2" with a probability of $50 \%$ and a " 4 " with a probability of $50 \%$. Each income event at this production stage was counted by multiplying each investment amount with the lotto result. If a participant invested $a_{1}(\in[0,100,200,300])$ and derives a lotto $q_{1}(\in[2,4])$, the production earning was $\pi_{1}=a_{1} q_{1}(0 \leqq \pi \leqq 1200)$. If one's pair invested $a_{2}$, derived a lotto $q_{2}$ and received production earnings $\pi_{2}=a_{2} q_{2}$ then the team's combined income became $\Pi=\pi_{1}+\pi_{2}(0 \leqq \Pi \leqq 2400)$.

\section{Distribution stage}

In distribution stage, a participant was asked to furnish a distribution proposal, which separated the total team's income into two shares, one for each individual in the pair. After the production stage, each participant was informed of the relevant figures on the screen: his investment $a_{1}$; his lotto result $q_{1}$; his earnings $\pi_{1}=a_{1} q_{1}$; his pair's investment $a_{2}$; her lotto result $q_{2}$; her earnings $\pi_{2}=$ $a_{2} q_{2}$ and the team' earnings $\Pi=\pi_{1}+\pi_{2}$ Then, in the same way as in the dictator game, he was asked to give a distribution proposal that divided the team's earnings between himself and his pair. After proposals were given, one of proposals offered by each member was randomly chosen and the individual's final profit was decided according to the proposal.

\section{Payment}

The total points of the individual's distributed final profit were added to a non-invested endowment was converted in terms of 1 point = 1 yen (100 yen is approximately \$1) and paid to each participant after the experiment.

\section{Fairness Ideals and Model}

\section{3-1. Fairness Ideals}

The self distribution amount based on a fairness ideal $m^{k(i)}$ that a participant $i$ may commit could be defined as following (see Hoffman et al. 1985; Cappelen et al. 2007) ${ }^{5}$ :

${ }^{5}$ Cappelen et al. (2007) also refers to a "liberal egalitarian," who distributes team earnings according 
1. Utilitarian: A utilitarian is defined as one who pursues self-profit and tries to maximize one's own utility. Thus, a strict utilitarian distributes all of a total team earnings to himself as: $m^{u}=$ $\Pi$

2. Egalitarian: An egalitarian thinks that total team earning should be distributed 50-50 with her pair. Thus, a strict egalitarian distribution for herself is described as: $m^{E}=\frac{1}{2} \Pi$

3. Liberalist: A liberalist thinks it is fair to distribute total team earnings according to the amount each member earned in the production stage. Thus, a strict liberalist distribution is: $m^{L}=\pi_{1}$

\section{3-2. Value Functions}

Following the Fehr \& Schmidt model, an individuals' value function for distribution can be expressed as a linear combination between material utility and fairness ideals (see also Cappelen et al. 2007). Given fairness ideal $\mathrm{m}^{k(i)}$ of a participant $i$, the distribution amount for himself $y$, the value function of a participant $i$ could be expressed as follows:

$$
V_{i}\left(y ; \pi_{1}, \pi_{2}\right)=\theta_{1} y-\theta_{2} \frac{\left(y-m^{k(i)}\right)^{2}}{2 \Pi} \quad \theta_{1}+\theta_{2}=1, \quad 0 \leq \theta_{1}, \theta_{2}
$$

$\theta_{1}$ is the load factor to his material utility and $\theta_{2}$ is the load factor to his fairness ideal. The first term in the right-hand-side formula is a utility function, and second term expresses that negative utility is produced as one's self distribution $y$ deviates from his fairness ideal $m^{k(i)}$. The self distribution amount $y^{*}$ that maximize $i$ 's value function $V_{i}$ is expressed as:

$$
\operatorname{Max} V_{i}: \frac{d V_{i}}{d y}=0 \quad y_{i}^{*}=m^{k(i)}+\frac{\theta_{1}}{1-\theta_{1}} \Pi
$$

One's optimum self distribution $y^{*}$ could be understood as a total of the ideal amount based on fairness ideals $m^{k(i)}$ and the amount a participant may add by selfish material utility $\frac{\theta_{1}}{1-\theta_{1}} \Pi$. Since $\lim _{\theta_{1} \rightarrow 0} y^{*}=m^{k(i)}$, one’s self-distribution amount $y^{*}$ approaches to ideal fairness amount as one’s load factor on material utility $\theta_{1}$ approaches zero ${ }^{6}$.

\section{3-3. Relative Earnings}

Instead of performing different experimental treatments, this study classifies participants'

to the amount each participant invested: $m^{L E}=\frac{a_{1}}{a_{1}+a_{2}} \Pi$. However, this paper does not take into account the liberal egalitarian concept the experimental design produces little evidence for it. ${ }^{6}$ Since utilitarianism is equal to completely selfish behavior, one's self-distribution amount $y^{*}$ approaches to a strict utilitarian as one's load factor on material utility $\theta_{1}$ approaches one: $\lim _{\theta_{1} \rightarrow 1} y^{*}=m^{U}=\Pi$. However, for comparisons with other fairness ideals, I do not take into consideration the case of $\theta_{1}=1$ in this paper. Instead, I regard utilitarian distribution as one of fairness ideals. 
distributional situations by the different parameters of each participant; an investment amount; a lotto result; total earnings; and relative earnings to examine whether or not participants fairness ideals depend on their distributional situation. One's relative earning is defined as one's earning amount compared with one's pair as explained below:

1. Neutral: Those participants whose earnings are the same with their pairs: $\pi_{1}=\pi_{2}$

2. High: Those participants whose earnings are higher than their pairs: $\pi_{1}>\pi_{2}$

3. Low: Those participants whose earnings are lower than their pairs: $\pi_{1}<\pi_{2}$

An individual's commitments to certain fairness ideals are examined with different distributional situations, to examine whether or not a participant's fairness ideal is coherent or instead strategically changes depending on the situation.

\section{Experimental Results}

\section{4-1. Statistical description}

Table 1 shows a statistical description of the experimental results. Three participants invested nothing, 32 participants invested 100 points, 53 participants invested 200 points, and 46 participants invested 300 points. The minimum amount of a participant's earning was 0 points, the maximum was 1200 points; the average was 622.38 points, and the mean was 600 points. The minimum amount of total team earnings was 400 points, the maximum was 2000 points, the average was 828.9 points, and the mean was 800 points. The average payment participants received was 716.42 yen. In Japan, average payments for students for an hour work is approximately 1000 yen (almost \$10), thus the game result fully satisfied participants’ opportunity costs.

Table 1: Statistical description

\begin{tabular}{lcccc}
\hline & $a$ & $\pi$ & $\Pi=\pi_{1}+\pi_{2}$ & $y$ \\
\hline Min. & 0 & 0 & 400 & 200 \\
Max. & 300 & 1200 & 2000 & 2000 \\
Average & 206 & 622.38 & 1245 & 828.9 \\
Mean & 200 & 600 & 1200 & 800 \\
\hline
\end{tabular}

4-2. Predicted value and measured value

According to the model defined in the previous section, the optimum distribution of a participant $i$ 's 
empirical value function is expressed as follows:

$$
y_{i}^{*}=m^{k(i)}+\frac{\theta_{1}}{1-\theta_{1}} \Pi+\varepsilon^{2}
$$

Where $\varepsilon^{2}$ expresses the error sum of squares. A participant distributes the amount of $y^{*}$, a total of ideal fairness distribution $m^{k(i)}$ and "the added amount by selfishness" $\frac{\theta_{1}}{1-\theta_{1}} \Pi$ to herself. As a participant's load factor $\theta_{1}$ to material utility increases, the "the added amount by selfishness" increases. Fairness ideals $m^{k(i)}$ for each participant were identified from three kinds of fairness ideals: utilitarian, egalitarian, and liberalist, which minimizes the error sum of squares $\varepsilon^{2}$.

Now, moving the load factor $\theta_{1}$ from 0 to 0.7 , I estimated whether the predicted value $y_{i}^{*}$ closely approximates the observed value y. Table 2 shows the results of their linear regression by load factor. As the load factor on material utility $\theta_{1}$ increases, the model does not fit well with the observed value: R-square decreases; and the Root Mean Square Error and Error average square decreases. Although p-value is satisfactorily small in each value, the t-value gets larger as the load factor $\theta_{1}$ is smaller. At the point of the load factor being zero $\left(\theta_{1}=0\right)$, the predicted value of the model closely approximates the measured value. Actually, $85 \%$ of the participants proposed the self-distribution amount, which is completely the same with the ideal amount of the other ideals of utilitarianism, egalitarianism or liberalism $\left(y^{*}=m^{k(i)}\right)$. Almost a half of the participants (7\%), who did not take the ideal amounts took amounts at the very middle of two of the three fairness ideals (e.g., $y^{*}=\frac{m^{E}+m^{L}}{2}$, see 4-3 and Table 3, Ambivalent).

These results show that most individuals tend to exclusively follow one distribution principle, and that some participants follow two fairness ideals simultaneously. Participants, those who added "some selfish amounts" to the ideal distributional amount $\frac{\theta_{1}}{1-\theta_{1}} \Pi$, were observed in just only a few (8\%). From these result we could derive following proposition:

- PROPOSITION 1: Individuals have a significant tendency to commit exclusively to one distribution principle to distribute earnings with other participants. 
Table 2: Linear Regression between predicted value and measured value (y) by loading factor

\begin{tabular}{llllll}
$\theta_{1}$ & $\mathrm{R}^{2}$ & $\begin{array}{l}\text { Root Mean } \\
\text { Square } \\
\text { Error }\end{array}$ & $\begin{array}{l}\text { Error average } \\
\text { square* }\end{array}$ & t-value & p-value \\
& \multicolumn{7}{c}{} & & \\
\hline$\underline{0}$ & $\underline{0.965476}$ & $\underline{74.55627}$ & $\underline{5558.6376}$ & $\underline{60.76}$ & $\underline{\underline{2}}$ \\
0.1 & 0.939584 & 98.6279 & 9727.4623 & 45.31 & $<0.0001$ \\
0.2 & 0.718631 & 212.8445 & 45302.795 & 18.36 & $<0.0001$ \\
0.3 & 0.621449 & 246.8804 & 60949.938 & 14.72 & $<0.0001$ \\
0.4 & 0.533314 & 274.1175 & 75140.409 & 12.28 & $<0.0001$ \\
0.5 & 0.497154 & 284.5392 & 80962.567 & 11.42 & $<0.0001$ \\
0.6 & 0.496532 & 284.7149 & 81062.586 & 11.41 & $<0.0001$ \\
0.7 & 0.492982 & 285.7171 & 81634.279 & 11.33 & $<0.0001$ \\
\hline
\end{tabular}

$*$ Degree of freedom $=132$

4-3. Fairness Ideals by Distributional situation

This model predicts best when the load factor on material utility is zero $\left(\theta_{1}=0\right)$; thus, I classified participants' distribution results into three different fairness ideals: egalitarian, liberalist, and utilitarian. Then, I examined the occurrence frequency of those fairness ideals by the relative earnings of participants, as shown in Table 3. Note that for the Neutral Group, the case of their relative earnings is the same. For $\pi_{1}=\pi_{2}$, one cannot distinguish a participant's preference for a liberalist ideal from an egalitarian one, since the distribution amounts according to them are the same in this case $\left(\pi_{1}=\Pi / 2\right)$. Actually, $80 \%$ of participants, who belong to neutral group, committed to egalitarian/liberalist distributions and the remaining 20\% distributed the entire earnings to themselves. This result is in line with previous distribution experiments that did not include production, and it suggests that the participants' group, or experimental environment, is not significantly different from those of previous studies (Forsythe et al. 1994).

As is shown in Table 3, a sharp contrast was observed in liberalist and egalitarian participants in terms of their relative earnings. Participants whose relative earnings were lower, significantly preferred the egalitarian distribution compared with those whose relative earnings were higher. By contrast, participants with higher relative earnings preferred the liberalist distribution while those whose relative earnings were lower tended to dislike that approach. Regarding utilitarianism, I could not find a significant difference for its occurring rate in terms of relative earnings. Participants who committed to a utilitarian distribution, i.e., those who left nothing to their pairs, were observed to act independently of their relative earnings ${ }^{7}$. From these results, I could derive following proposition:

7 I also conucted different version of the experiment: instead of deriving lotto, participants were asked to take Synthetic Personality Inventory (SPI) test, a kind of IQ test, inner 10 minutes. All participants' SPI papers were 
- $\quad$ PROPOSITION 2: An individual whose relative earnings are high compared with his pair displays a significant tendency to commit to a liberalist distribution; an individual whose relative earnings are low displays a significant tendency to commit to an egalitarian distribution.

Table 3: Occurrence frequency of fairness ideals by parameters in distribution

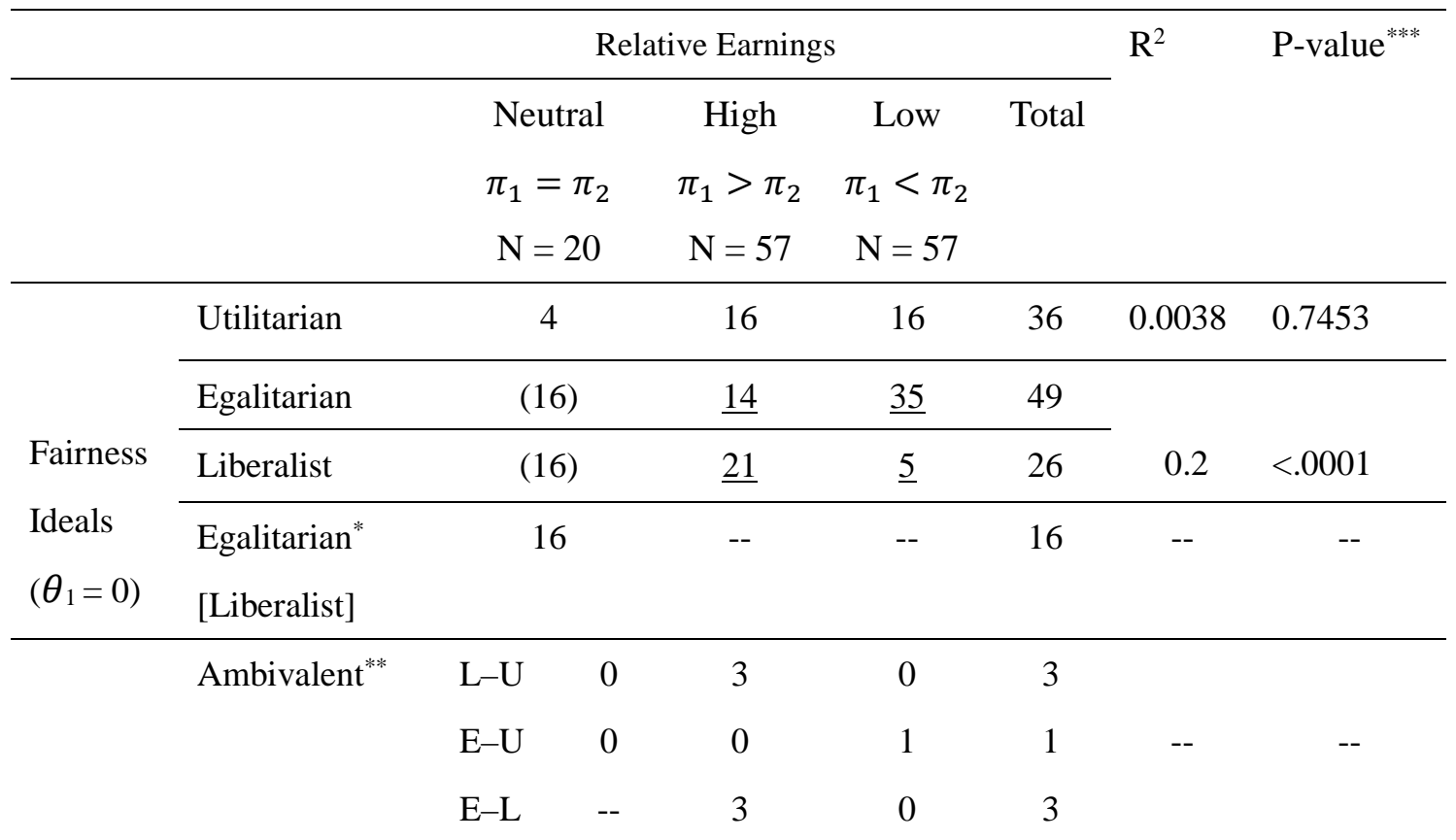

* Egalitarian [Liberalist] participants in neutral group overlaps egalitarian with liberalist distribution; because the distribution could be understood as both of egalitarian and liberalist when individual's earnings is the same with his pair $\left(\pi_{1}=\pi_{2}\right)$, and he distributes total team income half to half. For estimation of $m^{E}$ and $m^{L}$, neutral participants are deselected from population.

** $m^{E-L} m^{E-U} m^{L-U}$ describes participants who take the middle amount between Egalitarian and liberalist distribution, egalitarian and utilitarian, and liberalist and utilitarian. For estimation of $m^{E}$ and $m^{L}$, neutral participants are deselected from population.

*** Estimated by Pearson’s chi-squared test.

\section{Discussion}

As is summarized in proposition 1, the experimental results of this study show that most participants (85\%) proposed distribution amounts that are completely compatible with one of the ideal amounts conforming to utilitarianism, liberalism, or egalitarianism. Seven percent of participants committed to the median amount between two of ideal amounts. This result is not congruent with the result " 4", while the rest 50 per cent get "2" instead. In SPI treatment, liberalists were observed a little more than Lotto treatment. However, significant tendencies were the same with Lotto treatment described here. 
expectation of the Fehr \& Schmidt model (1999) that describes the optimum distribution $y^{*}$ in terms of the total of ideal amount $m^{k(i)}$ and that considers the "added amount by selfish incentive” $\frac{\theta_{1}}{1-\theta_{1}} \Pi$. Graph I shows that one’s optimum distribution for oneself $y^{*}$ expected by Fehr \& Schmidt's value function, as amounts of one's ideal fair distribution (egalitarian or liberalist) with additional selfish amounts. The dotted horizon line of Graph 1 expresses egalitarian ideal amounts: $y^{*}=\frac{1}{2} \Pi$; egalitarian participants are expected to take the amounts on the upper- shifted line $y^{*}=$ $\frac{1}{2} \Pi+\frac{\theta_{1}}{1-\theta_{1}} \Pi$. Similarly, liberalist participants are expected to take the slash line shifted from the dotted slash line $y^{*}=\pi_{1}$, which expresses liberalist ideal amounts, because of "additional amounts by selfish incentives” $\frac{\theta_{1}}{1-\theta_{1}} \Pi$. However, those additional amounts are observed in few participants in the experiment and the reason should be explained.

According to Festinger (1957), those individuals with contradictory beliefs in their minds, and with mental discomfort, reflect what he calls “cognitive dissonance.” And individuals experiencing cognitive dissonance try to resolve the psychologically uncomfortable situation by changing their beliefs. For instance, a fox in Aesop's fables, having failed to catch a grape, tried to resolve his cognitive dissonance between his desire for eating grapes and the situation of frustration, by changing his belief from "the grape is sweet" to "the grape is bitter." The experimental results, that an individual would have committed to one certain distribution principle, could be understood as outcomes in which participants attempted to resolve their "cognitive dissonance," which happens in those minds with contradictory cognitions. Committing to a certain distribution principle may be followed by one’s efforts to resolve cognitive dissonance (see also Konow 2000) ${ }^{8}$.

${ }^{8}$ Rabin (1994) states that those cognitive dissonance decreases people’s commitments to reciprocity, since they cannot be completely ethical then just commit to selfish behavior without cognitive dissonance. 


\section{[Graph I] Fehr\&Schmidt Model distribution}

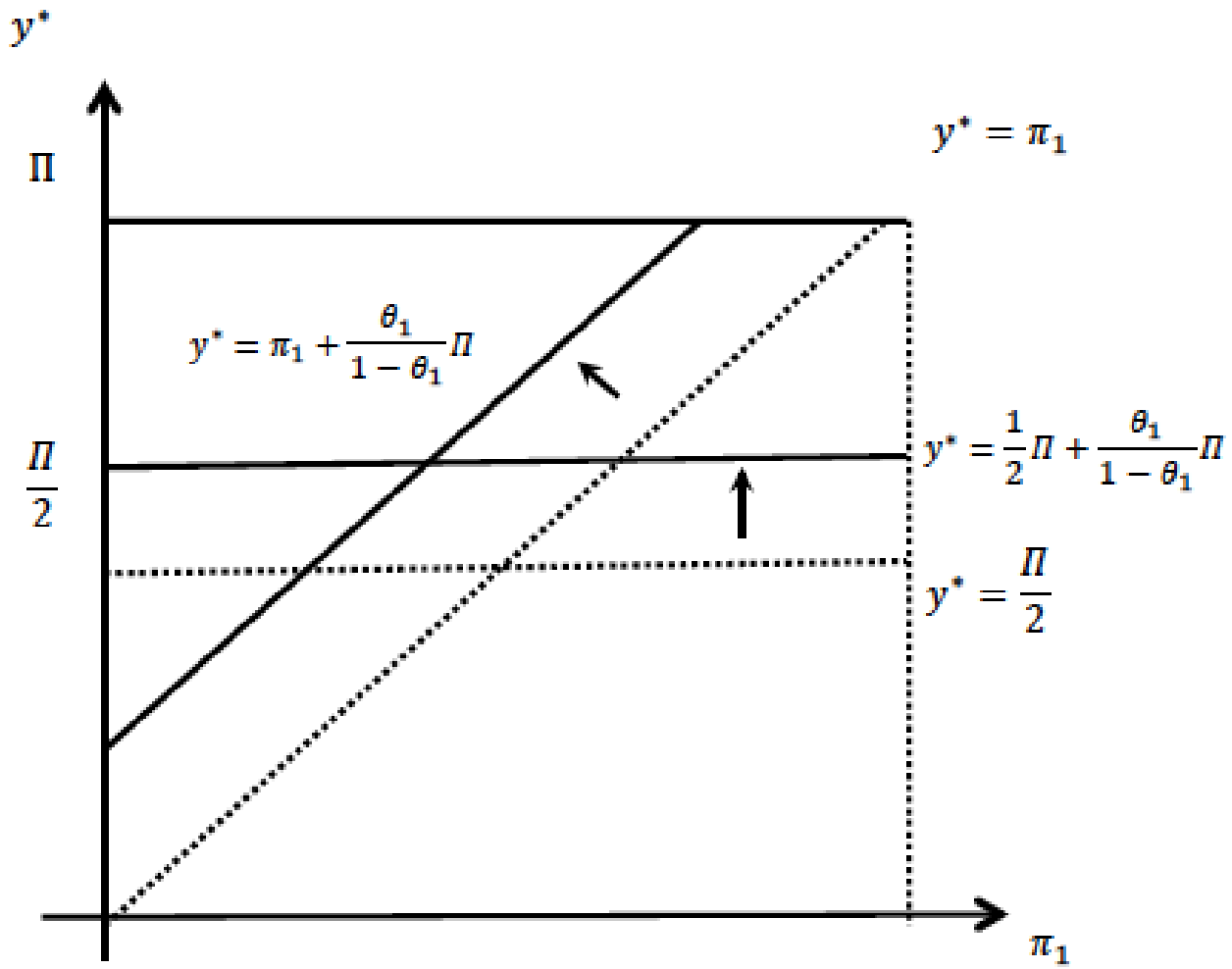

Proposition 2 summarizes the experimental results that a participant's commitment to liberalist or egalitarian fairness ideals depends on their relative earnings to a significant degree. In the experiments, participants whose relative earnings were higher compared with their pairs displayed a significant tendency to commit to a liberalist distribution, whereas those whose relative earnings were lower tended to be egalitarian. This result contrasts with previous studies that presuppose an individual's fairness ideals are fixed under the same experimental institution (Hoffman et al. 1985; Cappelen et al. 2007). Thus the reasons why such tendencies are observed should be explained.

The experimental results may show that individuals who pursued opportunistic behavior, i.e., who selected more advantageous fairness ideals (to satisfy distributive justice and their selfishness) did so as a result of their resolving cognitive dissonance. Graph II describes relation between relative earnings and fairness ideals. The left half of Graph II indicates the range of lower relative earnings $\left(\pi_{1}<\frac{1}{2} \Pi \leftrightarrow \pi_{1}<\pi_{2}\right)$ and the rest of right half indicates the range of higher relative earnings $\left(\pi_{1}>\frac{1}{2} \Pi \leftrightarrow \pi_{1}>\pi_{2}\right)\left(\because \Pi=\pi_{1}+\pi_{2}\right)$. Where relative earnings are lower, egalitarian distribution $\mathrm{y}=\frac{1}{2} \Pi$ always brings a higher self-distribution $\mathrm{y}$ than a liberalist distribution $y=\pi_{1}$; where relative earnings are higher a self-distribution based on liberalist principles is always higher than that of egalitarian choices, and vice versa. As the arrows show in Graph II, participants may shift their fairness ideals from liberalist to egalitarian where relative earnings are lower and from egalitarian to 
liberalist where relative earnings are higher. If the participants' fairness ideals are coherent and independent of their relative earnings, those participants embedded in egalitarianism should always distribute their team earnings 50-50, whereas participants embedded in liberalism should distribute the same amount that they also earned. Such fundamentalist behaviors can be observed, but they are not common. Many participants prefer the fairness ideals that bring them higher relative earnings: individuals with higher relative earnings display a significant preference to commit to a liberalist distribution, whereas those with lower relative earnings prefer to commit to an egalitarian distribution ${ }^{9}$.

Williamson (1975) describes opportunistic behavior in terms of individuals seeking self-interest "with guile" without deviating from social norms or rules. If a participant determines the self-distribution amount by adding a "selfish amount" to the ideal fair amount, as shown in Graph I, then his selfishness is also exposed in the added amounts. However, if an individual "commits” to one of the more advantageous fairness ideals, as expressed in Graph II, then her selfishness is hidden under the selected ideal amounts. On the surface, she seems to be a strict liberalist or egalitarian individual, without adding the selfish amount to the self-distribution. As is argued by Levitt and List (2007), social norms are also important motivations for individuals, as well as morals. If an individual exposes his selfishness to the others in an obvious way, he may be afraid of receiving a social sanction for violating norms. Individuals with different directional incentives of fairness and selfishness might strategically "select” one of more advantageous fairness ideals from two possible distribution opportunities, rather than expose their selfishness by adding "selfish amounts" to the ideal fair shares. Here, we can discover behavior that does not completely deviate from distributive justice, but statistically makes use of given opportunities with hidden and selfish incentives. By committing opportunistic behavior, an individual may be able to satisfy his selfish incentives in some extent, without deviating social norms.

\footnotetext{
${ }^{9}$ Bolton and Ockenfels (2000) argues that a relative payoff compared with others is an important motivation for individuals.
} 


\section{[Graph II] Opportunist distribution}

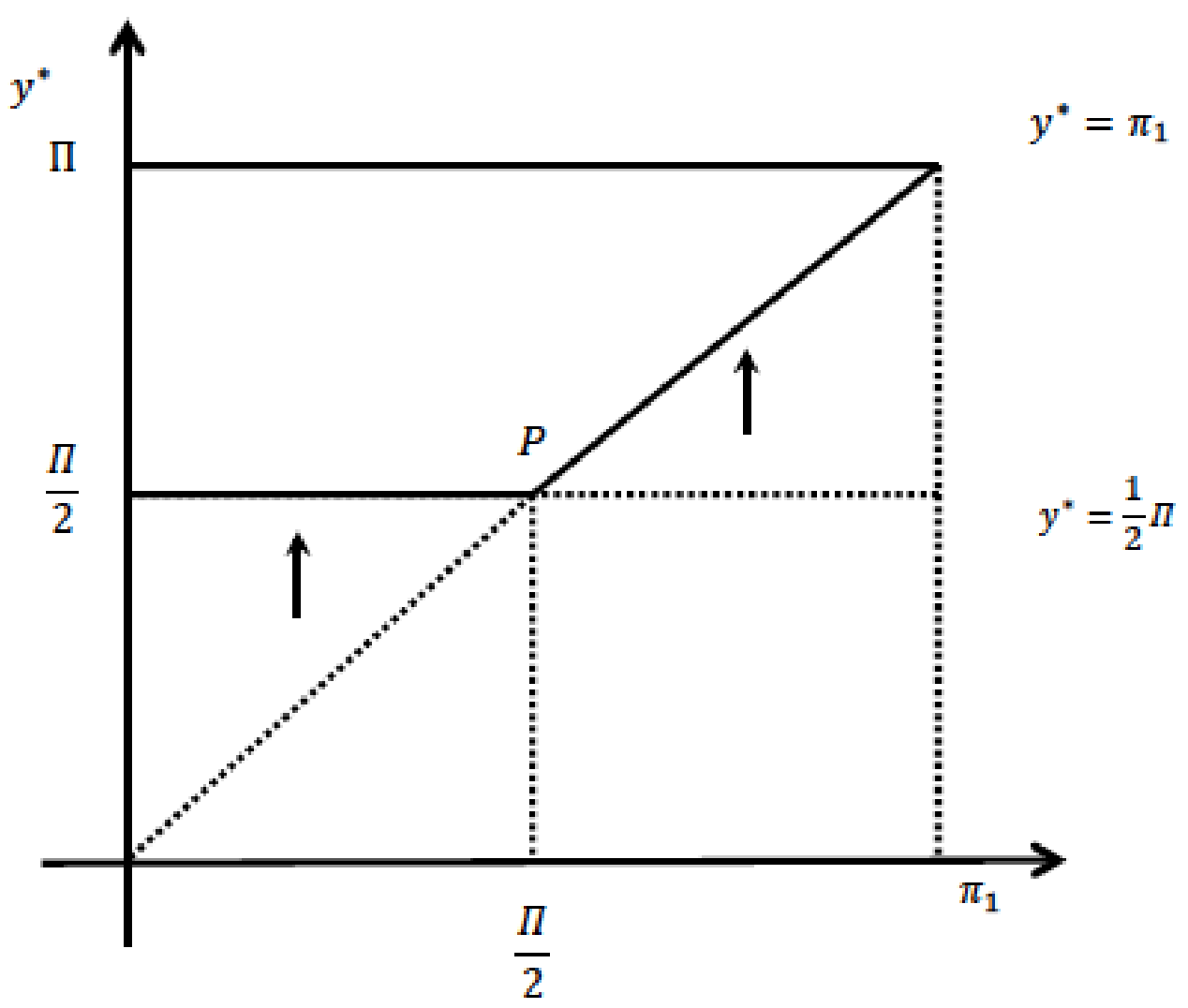

\section{Conclusion}

This paper demonstrated that many individuals do not fundamentally commit to a certain fairness ideal invoked by a certain experimental institution; instead, they strategically select one advantageous "fair" distribution principle from several possible fairness ideals. If an individual is not a strict utilitarian, willing to ignore social norms and to pursue selfish behavior, then he tends to prevent his selfish motivation being brought to the surface. Instead, he may strategically "select” a more profitable fairness ideal without adding any selfish amount, to hide his selfishness and satisfy ethical (or social) justifications - all to resolve the cognitive dissonance between material utility and fair distribution. Table 4 summarizes three different individual behaviors that emerged from fairness ideals and material utility. Behavior A describes some participants as fundamentally liberalist or egalitarian, and who remain faithful to a given distributive justice and then distribute earnings according to a coherent set of fairness ideals, independent of the situation. Behavior $B$ reveals the more opportunistic behavior of individuals who change their fairness ideals by making use of the given opportunities of relative earnings ${ }^{10}$. Their incentives come from both fairness ideals (adhering

\footnotetext{
${ }^{10}$ In the experimental results shown in Table 3, the R-square value of liberalist and egalitarian by relative earnings were not so high $\left(R^{2}=0.2\right)$, because I cannot excluded out few fundamentalists from opportunists, but $\mathrm{p}$-value confirms that occurrence rate of fairness ideals by relative earnings are significantly different ( $\mathrm{p}$
} 
to social norms) and from hidden selfishness (to satisfy their material utility). Behavior C describes those who are purely motivated by material utility, and who have no reluctance to hide their selfish incentives.

Opportunists should not be classified as purely selfish individuals or purely ethical ones, since both of these two incentives are simultaneously present, and thus the individuals strategically hide their selfish incentives and assume the behavior of a "fair" person. Those who pursue opportunistic behaviors may be in cognitive dissonance between distributive justice and selfishness, and then strategically take advantage of different opportunities. By behaving in an opportunistic way, individuals may be able to satisfy their selfishness inner social norms or given institutional conditions.

Table 4. Incentives and Behaviors

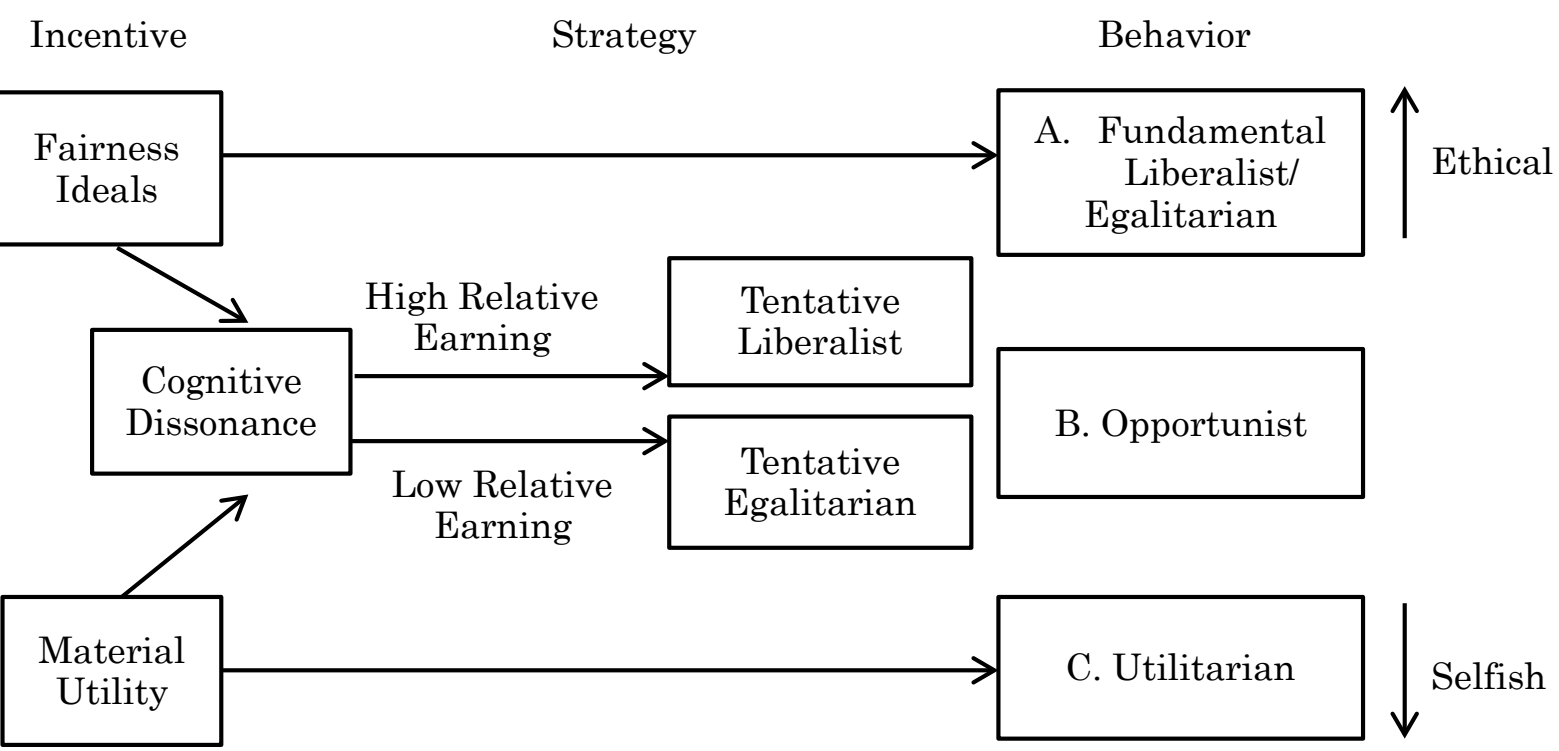

References

1. Bolton, G. E., and Ockenfels, A. (2000), "ERC: A Theory of Equity, Reciprocity, and Competition,” The American Economic Review, 90(1), 166-193.

2. Cappelen, A. W., Hole, A. D., Sorensen. E. O., and Tungodden, B. (2007), "The Pluralism of Fairness Ideals: An Experimental Approach,” The American Economic Review, 97(3), 818-827.

3. Cappelen, A. W., and Tungodden, B. (2009), "Rewarding Effort,” Economic Theory, 39(3), 425441.

4. Cappelen A. W., and Tungodden, B. (2011), "Distributive Interdependencies in Liberal Egalitarianism,” Social Choice and Welfare,36(1), 35-47. 
5. Cherry, T. L., Frykblom, P., and Shogren, J. F. (2002), "Hardnose the Dictator," The American Economic Review, 92(4), 1218-1221.

6. Dana, J., Weber, R. A., and Kuang, J. X. (2007), “Exploiting Moral Wiggle Room: Experiments Demonstrating an Illusory Preference for Fairness,” Economic Theory, 33(1), 67-80.

7. Engelmann, Dirk \& Strobel, Martin (2004), “Inequality Aversion, Efficiency, and Maximin Preferences in Simple Distribution Experiments,” The American Economic Review, Vol., 94, No.4, 857-869.

8. Eckel, C.C., and Grossman, P. (1996), “Altruism an Anonymous Dictator Games,” Games and Economic Behavior, 16, 181-191.

9. Fehr, E., and Schmidt, K. M. (1999), “Theory of Fairness, Competition, and Cooperation,” The Quarterly Journal of Economics, 114(3), 817-868.

10. Festinger, L. (1957), A Theory of Cognitive Dissonance, Stanford University Press.

11. Fischbacher, U. (2007), “z-Tree: Zurich Toolbox for Ready-made Economic Experiments," Experimental Economics, 10(2), 171-178.

12. Forsythe, R., Horowitz, J.L., Savin, N.E., and Sefton, M. (1994), "Fairness in Simple Bargaining Experiments," Games and Economic Behavior, 6(3), 347-69.

13. Frohlich, N., Oppenheimer, J., and Kurki, A. (2004), "Modeling Other-Regarding Preferences and an Experimental Test,” Public Choice, 119(1-2), 91-117.

14. Hoffman, E., and Spitzer, M. L. (1985), "Entitlements, Rights, and Fairness: An Experimental Examination of Subjects’ Concepts of Distributive Justice,” Journal of Legal Studies, 14, 259297.

15. Hoffman, E., McCabe, K., and Smith, V.L. (1996), "Social Distance and Other Regarding Behavior in Dictator Games,” American Economic Review, 86, 653-660.

16. Kahneman, D., Knetsch, J. L., and Thaler, R. H. (1986), "Fairness and the Assumptions of Economics,” Journal of Business, 59(4). S285-S300.

17. Konow, J. (2000), "Fair Shares: Accountability and Cognitive Dissonance in Allocation Decisions,” The American Economic Review, 90(4), 1072-1091.

18. Levin, D. K. (1998), "Modeling Altruism and Spitefulness in Experiments", Review of Economic Dynamics 1, July, 593-622.

19. Steven D. Levitt and John A. List (2007), "What Do Laboratory Experiments Measuring Social Preferences Reveal About the Real World?”, Journal of Economic Perspectives, 21, 153-174.

20. List, J. A. (2007), “On the Interpretation of Giving in Dictator Games,” Journal of Political Economy, 115(3), 2007.

21. Rabin, M. (1994), “Cognitive Dissonance and Social Change,” Journal of Economic Behavior and Organization, 23(2), 177-94 
22. Ruffle, B. J. (1998), "More is Better, Bit Fair is Fair: Tipping in Dictator and Ultimatum Games,” Games and Economic Behavior, 23, 247-265.

23. Williamson, O. E. (1975), Markets and Hierarchies, The Free Press, A division of Macmillan Publishing Co., Inc.

\section{Appendix}

Economic Experiment: Instruction

Thank you very much for your participation in an economic experiment. Before the experiment starts, the experimenter explains rules of the experiment by this instruction. Please read this instruction carefully and raise your hands to ask a question if you are unclear about anything. Please do not start the game until the experimenter says "please start the game”.

1. Ini tial endowm ent points: 300

points are given to you as initial endowments for this game. You can invest the points to lotto game by 100 points. You can invest all of the initial endowment points or invest none of them. That is, you can select investment amounts out of 0 point, 100 points, 200 points and 300 points. Rest points that are not invested are counted in your final profits.

2. Lotto:

You will derive lotto in the game. In $50 \%$ probability the lotto is attributed to "4” (very lucky) and "2" (lucky) in the rest $50 \%$. The number which multiplies your investment amounts to your lotto result is counted as your earning points.

e.g., In case you invested 100 points and derived lotto “4” (very lucky).

Your earning points: $100 \times 4=400 \quad 400$ points

3. Pair (two-member team):

You are pair-matched with someone out of participants and make two members team. A participant, who becomes your pair, is randomly chosen. Information on whose pair is who is unknown to you, all of other participants, and experimenters as well during and after the experiment.

4. Team earnings:

Your earnings and your pair (your team member)'s earnings are summed up and makes team earnings. Team earnings are shown to you and your pair in each screen with information on each investment point; each lotto result; each earning. 


\section{Distribution proposal}

After team earnings are shown in the screen, please propose distribution proposal, which shares the team earnings into you and your pair. The total amount of your distribution points and your pair's distribution points should be the same with the team earnings.

e.g. Team earning points: 1000

Distribution for myself: 500; distribution for my pair: 500

6. Final profit of lotto game

One of the distribution proposals proposed by you and your pair is randomly chosen. According to the chosen distribution proposal, the team earnings are distributed as lotto game profits. The points you have not invested are counted as your final profits.

7. Points conversion and payments

Points are counted as 1 point $=1$ yen, and paid after the experiments finishes.

If you have anything you cannot understand about the game, please raise your hand. 